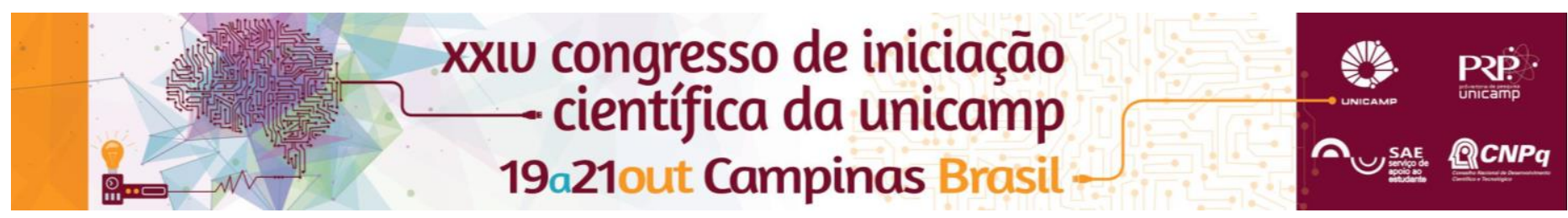

\title{
Expressão de genes relacionados à via de sinalização TGFbeta1 / SMAD na Doença do Enxerto contra o Hospedeiro crônica
}

\author{
Beatriz Corey Morini ${ }^{\star}$, Marcos Paulo Colella, Matheus Rodrigues Lopes, Francisco José Penteado Aranha, \\ Cármino Antonio de Souza, Afonso Celso Vigorito, Sara Olalla Saad, Patricia Favaro.
}

\section{Resumo}

A Doença do Enxerto contra o Hospedeiro crônica $(\mathrm{DECHc})$ é uma complicação frequente após o transplante de medula óssea. Ela ocorre devido a uma reação do enxerto contra as proteínas do hospedeiro. Evidências na literatura apontam que a via do TGF-b tenha um papel na DECHc. Desta forma, este trabalho foi avaliar a expressão de transcritos de TGFbeta1 e seus alvos SMAD4 e SMAD5 em células mononucleares do sangue periférico de pacientes submetidos ao transplante alogênico de medula óssea e também de controles saudáveis a fim de entender a via de sinalização do TGF-beta na DECHc.

Palavras-chave:

TGF beta,transplante alogênico de células-tronco hematopoiéticas, Doença do Enxerto contra o Hospedeiro crônica $(\mathrm{DECHc})$.

\section{Introdução}

A Doença do Enxerto contra o Hospedeiro crônica (DECHc) é um distúrbio imunológico que se desenvolve após o transplante alogênico de células-tronco hematopoiéticas, no qual as células $\mathrm{T}$ do doador produzem resposta imune contra proteínas do hospedeiro ${ }^{1}$. Ela é uma das complicações mais importantes do transplante alogênico de células-tronco hematopoiéticas, devido à mortalidade e ao impacto na qualidade de vida do paciente ${ }^{2}$. A fisiopatologia da $\mathrm{DECHc}$ não está ainda bem compreendida, mas há uma hipótese de que células Tregs Foxp3 $^{+}$suprimam o enxerto contra as reações do hospedeiro ${ }^{3}$. Estudos sugerem que a supressão ocorre através de citocinas como TGF- $\beta$ e IL-10. ${ }^{4}$ TGF- $\beta$ é uma citocina que regula o desenvolvimento, homeostase e diferenciação de células $\mathrm{T}^{5}$. Sabe-se também que TGF- $\beta$ induz a expressão de Foxp3 e o fenótipo Treg nas células $\mathrm{T} \mathrm{CD}^{+}$virgens, entretanto, o mecanismo transcricional ainda permanece incerto ${ }^{3}$.

O objetivo deste trabalho foi avaliar a expressão de transcritos de TGF $\beta 1$ e seus alvos SMAD4 e SMAD5 em células mononucleares do sangue periférico de pacientes submetidos ao transplante alogênico de células-tronco hematopoiéticas e também de controles saudáveis.

\section{Resultados e Discussão}

Um total de 13 amostras de dadores saudáveis (mediana de idade $=44,5$, intervalo de $26-55$ ) e 18 pacientes (mediana-idade $=43$, intervalo $23-68$ ) submetidos a transplante alogênico foram incluídos. A expressão de RNAm foi detectada por PCR quantitativo. Além do controle (13 doadores suadávies), os pacientes foram divididos nos 3 grupos: 1) DECHc, recebendo tratamento imunossupressor (TIS) - (5 pacientes); 2) DECHc sem TIS - (7 pacientes); e 3) Tolerante, sem histórico de DECHc ou após 6 meses de recuperação da DECHc - $(5$ pacientes). Foi utilizado o teste de Mann-Whitney para análise dos resultados, sendo que valor de $p<0,05$ foi considerado estatisticamente significativo ${ }^{7}$. O grupo de
DECHc sem TIS apresentou uma diminuição significativa na expressão de TGF $\beta 1(p=0,01)$ e SMAD4 $(p=0,04)$ quando comparado com o controle.

Foi observada uma tendência similar para os níveis de expressão SMAD5. Além disso, o nível de TGF $\beta 1$ foi significativamente aumentado no grupo Tolerante quando comparado com o grupo DECHc sem TIS.

\section{Conclusões}

TGF- $\beta$ é uma citocina pleiotrópica com propriedades imunomoduladoras, implicadas na indução de tolerância específica do aloantigénio ${ }^{3}$. Nossos resultados sugerem uma associação de aumento da expressão de TGF- $\beta$ com um risco reduzido de DECHc. Entretanto, mais estudos são necessários para elucidar o mecanismo de regulação TGF- $\beta$ na DECHc.

\section{Agradecimentos}

Meus sinceros agradecimentos à FAPESP que faz possível a realização deste projeto de pesquisa e ao Instituto Nacional de Ciência e Tecnologia do Sangue INCT do Sangue.

1 - Lee, S.J., Vogelsang, G. \& Flowers, M.E. Chronic graft-versus-host disease Biol Blood Marrow Transplant 9, 215-33 (2003)

2 - Li, Q. et al. Decrease of CD4(+)CD25(+) regulatory T cells and TGF-beta at early immune reconstitution is associated to the onset and severity of graftversus-host disease following allogeneic haematogenesis stem cell transplantation. Leuk Res 34, 1158-68 (2010)

3 - Chen, W. et al. Conversion of peripheral CD4+CD25- naive T cells to CD4+CD25+ regulatory T cells by TGF-beta induction of transcription factor Foxp3. J Exp Med 198, 1875-86 (2003).

4 - Maloy, K.J. \& Powrie, F. Regulatory T cells in the control of immune pathology. Nat Immunol 2, 816-22 (2001).

5 - Coomes, S.M. \& Moore, B.B. Pleiotropic effects of transforming growth factor-beta in hematopoietic stem-cell transplantation. Transplantation $\mathbf{9 0}$, 1139-44 (2010) 